\title{
A Study on the Internationalization of Higher Education in Hainan under the Background of the Construction of Free Trade Pilot Zone
}

\author{
Lin Zhu ${ }^{\mathrm{a}}$ \\ Hainan College of Economics and Business, Gui Lin-yang Town, Haikou, Hainan, China
}

\begin{abstract}
With deepening economic globalization and increasingly fierce international competition, the internationalization of higher education has become an important trend in the whole world in the 21 st century. In 2018, Chinese government proposed to build Hainan Free Trade Pilot Zone. From this, Hainan university and colleges will undertake the important task of training international talents. Based on the study and analysis of the connotation and present situation of the internationalization of higher education in Hainan, this paper puts forward the countermeasures of the internationalization of Hainan higher education, aiming at providing basis and reference for the internationalization of talents training in Hainan universities and colleges.
\end{abstract}

\section{Introduction}

Under the background of globalization of world economy, informatization of society, internationalization of higher education has become the trend of education development. In the outline of National Medium and Long Term Education Reform and Development Plan (2010-2020), promulgated by the State in 2010, it was clearly put forward that we should carry out multi-level and wideranging educational exchanges and cooperation in order to improve the level of education internationalization in China.

On April 13, 2018, Chinese President Xi Jin proposed to build Hainan Free Trade Pilot Zone, and support the establishment of international energy and shipping commodities trading sites in Hainan. Hainan will be built as a pilot area for deepening reform and opening up in an all-round way, and an international tourism consumption center and a major national strategic service guarantee area.

With the construction of Hainan Free Trade Pilot Zone, the problem of talent shortage in Hainan has become increasingly prominent, especially the serious lack of high-level, compound and internationalized talents. In May 2018, Hainan Provincial Government issued the Action Plan for Millions of Talents Entering Hainan (2018-2025), and Notice of the Action Plan for Improving the Foreign Language Proficiency of the Citizens of Hainan Province, in January 2019, in order to cultivate Hainan citizens' open awareness, cultural literacy, intercultural communicative competences and mastering a foreign language so as to meet the need of building Hainan Free Trade Pilot Zone. Hence, how to promote the internationalization of Hainan's high education and effectively serving the construction of Hainan Free Trade Pilot Zone has become the hotspot of Hainan education research.

\section{The connotation of internationalization higher education}

Higher education internationalization refers to the expansion of the opening up of higher education of a country, including the perspective of cross-culture and internationalization, the exchange and cooperation of higher education institutions between countries, the participation in international education affairs, the improvement of international academic status. The meaning of internationalization of higher education covers a wide range of areas. Scholars and experts at home and abroad have carried out many studies on it. The representative views are as follows:

In 1980, Clark Kerr, an American scholar, put forward the concept of internationalization of higher education. He pointed out that "we need a new concept of higher education that transcends the tradition of land-grant colleges, which means that higher education should face the world, or that higher education should be internationalized.". Arum and Water believe that internationalization of higher education mainly includes three important factors: the international content of courses, the international flow of teachers and students, and the elements of international technical assistance and cooperation programs. J. Knight, a famous Canadian scholar, defines internationalization at the university level from the process of integration and development, that is, the process of integrating international dimension and 
cross-cultural dimension into the teaching, scientific research and service functions of universities. This concept combines the internationalization of education with the functions of universities. Laid believes that internationalization of higher education is a process of integrating the teaching, research and service functions of institutions of higher learning into an international or cross-cultural dimension.

Chinese scholars, Chen Xuefei and Liu Guihua regard the concept of internationalization of education as one of the main elements of internationalization of higher education. Zhou Wending, defines the concept of internationalization of higher education as "the process and result of the opening and exchange of higher education among nations". Liu Guihua points out that "internationalization of education concept" as one of the main elements of internationalization of higher education. Others believe that internationalization of higher education should not only embody internationalization in form and elements, but an attitude, consciousness and spirit, which is regarded as the representative of "atmosphere theory" of internationalization of higher education.

The author believes that the internationalization of higher education has rich connotations and involves a wide range of aspects, including educational philosophy, system design, personnel training mode, curriculum system, teaching staff and international cooperation and exchange etc.

\section{Analysis on the internationalization of higher education in Hainan}

\subsection{Policy and mechanism needs to be improved}

In May 2015, Hainan Provincial Government promulgated the Measures for Implementing the Introduction of Overseas High-level Talents. In June 2016, Hainan Provincial Education Department issued the Guidelines for the Declaration of Chinese-foreign Cooperation in Schools of Higher Education in Hainan Province. in March 2017, Hainan Provincial Government issued the Comprehensive Reform Plan for Education in Hainan Province, Article 21 of which states that Opening education to the outside world should be expanded, foreign high-quality educational resources is to be introduced, various forms of Sino-foreign cooperative school-running should be carried out. In March 2018, the Proposal on speeding up the internationalization of higher education in Hainan put forwarded by Liao Qinglin, member of the Ministry of Education, was approved. The above policies have played a great role in promoting the internationalization of higher education in Hainan, but there is still lack of related supporting policies to ensure the further implementation of the above policies. In order to speed up the internationalization of higher education in Hainan, we must improve the policy mechanism as soon as possible.
3.2 The internationalization of universities and colleges in Hainan started late and with a small scale

The internationalization of higher education in Hainan started late, and with a small scale. At present, there are about 20 universities and colleges in Hainan, including 7 undergraduate colleges and 13 tertiary colleges, but only nine of them have internationalization projects. The internationalization of education is more active in Hainan University and Hainan Tropical Ocean University. In May 2017, Hainan University and Arizona established HNU-ASU Joint International Tourism College, which was a break through in the realization of Chinese-foreign cooperative sponsoring institutions in Hainan Province. In June 2017, the Ministry of Education formally approved the establishment of Hainan Tropical Ocean University Malaysia Research Center. However most of the universities and colleges only stays in the projects such as academic exchanges, students' internship abroad, teachers' visits abroad or further studies. Some universities and colleges even do not have institutions specially responsible for international exchanges and fail to make rational and scientific plans for internationalization of education.

\subsection{An international teaching staff has not yet formed}

Due to the late development of the internationalization of higher education in Hainan, the internationalization of teachers in various universities and colleges is insufficient. Although teachers come from all over the country, there are not many who really receive education abroad. Teachers' concept of internationalization has not yet been formed, professional knowledge and teaching skills have not been updated in time. Although some universities and colleges offer opportunities for teachers to participate international exchange or international cooperation projects, but this kind of opportunities are still limited. In short, there is not yet a large-scale, high-quality teaching staff with international vision, and strong teaching ability.

\section{Countermeasures of internationalization construction of Hainan universities and colleges}

\subsection{Enhancing the concept of international school-running}

Internationalization is an important feature of educational modernization, and it is the inevitable requirement for the development of universities and colleges. Only by constantly updating the concept of running a school, clearly recognizing the importance of internationalization of higher education, combining with the urgent need for internationalized talents in the construction of Hainan Free Trade Pilot Zone, absorbing the advanced practices of foreign excellent universities, it is possible for Hainan 
universities and colleges to take a sustainable development path.

\subsection{Building an internationalized campus culture}

The construction of internationalized campus culture is of great significance to the construction of internationalized universities and colleges. The internationalized campus culture mainly includes four aspects: spiritual culture, material culture, activity culture and institutional culture construction. Universities and colleges should strengthen their propaganda work, establish associations, carry out all kinds of beneficial activities, and create a strong and diverse international campus culture atmosphere with inclusiveness and openness. Firstly, we can use campus network, WeChat, school newspaper or campus bulletin board to publicize knowledge and information related to international exchange and cooperation. Secondly, we should hold various thematic cultural festivals and stylistic competitions which are popular with Chinese and foreign students, so as to enhance the communication and understanding between Chinese and foreign teachers and students. Finally, international teacher-student organizations and associations should be established to give full play to the subjective initiative of Chinese and foreign teachers, returnees of overseas students, and to strengthen the management of foreign students.

\subsection{Establishing international education standards}

Education standards should be established. Talents are an important force of the construction of Hainan, and Free Trade Pilot Zone. Therefore, the primary task of the internationalization of higher education is to train international talents. Based on the market orientation, we should establish professional and objective of personnel training, and set up professional standards and curriculum system corresponding to the international vocational education standards, so as to ensure that the education qualification criteria and curriculum standards can be applied to the construction of Hainan Free Trade Pilot Zone.

\subsection{Building an internationalized professional curriculum system}

Under the background of the development of Hainan Free Trade Pilot Zone and economic globalization, China's economic structure is undergoing rapid economic transformation and industrial upgrading, and international competition is becoming more intense. This requires that higher education must take the training of international talents as an important work in the process of internationalization. Constructing an international curriculum system is the fundamental guarantee for the internationalization of education and the cultivation of international talents. We should introduce an advanced curriculum system from abroad, integrate domestic and foreign curricula, build a number of high-quality online open courses, fine teaching materials and Englishlanguage courses, create a number of brand majors with international influence, and provide students with a variety of personalized course choices, so as to cultivate talents who have an international perspective, understand international rules, and participate in international affairs and competition.

\subsection{Building an international teaching staff}

Building an international teaching staff is the key to realize the internationalization of higher education in Hainan. According to the actual needs of the construction of the Hainan Free Trade Pilot Zone and International Tourism Island, universities and colleges should formulate a training plan for the internationalization of teachers, broaden teachers 'international vision and concept through various forms and approaches including professional training, lectures exchange, and foreign education aid. We should vigorously implement the "Intellectual Introduction" Project so as to draw some outstanding foreign experts, technicians, frontline teachers and other personnel to enrich the domestic teaching staff.

\subsection{Improving the system and mechanism of international school-running}

The internationalization of higher education is a systematic project. Universities and colleges should establish and improve the leading institutions and systems for internationalization, and effectively solve the problems existing in the actual operation process such as the implementation of internationalization of teacher training projects, international exchange, funding teachers and students for abroad further study, increasing the proportion of foreign students with academic qualifications, establishing a system of Chinese cultural experience and practical practice for foreign students, as well as international school assessment, which provides institutional guarantees for the internationalization of Hainan universities and colleges.

\section{Conclusion}

In the wave of internationalization, the internationalization strategy has become more and more important in the development of higher education in various countries. In order to realize the national strategy of building Hainan Free Trade Pilot Zone, Hainan is in great need of internationalized talents who are with international perspective, familiar with international rules, and are able to participate in international affairs and international competition. For this reason, Hainan should set up relevant policies to provide institutional guarantees. All universities and colleges should speed up the pace of internationalization, by updating the concept, rendering the international cultural atmosphere, introducing the international curriculum, building an international teaching staff, so as to cultivate high-quality talents that meet the needs of the society and achieve a magnificent plan for the construction of Hainan Free Trade Pilot Zone. 


\section{Acknowledgement}

This research was financially supported by the China Institute of Higher Education Vocational and Technical Education Branch (Research on Strengthening Sinoforeign Cooperation in Running Schools in Higher Vocational Colleges and Improving the Quality of Talents Training, GZYYB2018147) and Hainan College of Economics and Business.

\section{References}

1. Deng Fengguang. A Study on Development of Education Internationalization around Guangdong's Normal Universities [D]. East China Normal University, 2018, 05.

2. Zhu Zhiya. Research on the Ways to Achieve the Internationalization of Higher Education in Local Universities [J]. Journal of kaifeng institute of education, 2018, 10, 20.

3. Jiang Wei. Research on internationalization development of Vocational Education in China under the background of "one belt and one road" [M]. Hubei University of Technology, 2018, 06, 01.
4. From Network: Hainan: Notice on the Issuance of Comprehensive Education Reform Program in Hainan Province, http: //gaokao.chsi.c//.

5. Jiang Lili. Cultivation of Communicative Competence in Teaching Chinese as a Foreign Language under the Background of Internationalization of Education [J]. Higher Education Forum, 2018, 03, 20.

6. Gu Yuanzhi. Research on the Internationalization Path of Higher Education in Henan Province [M]. Zhengzhou University, 2016. 05. 01.

7. Mei Lin, Yuan Hong. Integration and Development of Internationalization and Nationalization of Higher Education [J]. New Northwest, 2018, 03, 02.

8. Jiang Kai, Zhang Junfeng. Basic Views on the Opening-up of Higher Education in China [J]. Tsinghua Journal of Education, 2017, 12, 20.

9. Li Feng. Thoughts on Internationalization of Construction Animation and Model Making Specialty [J]. Art Major, 2017, 12, 15.

10. Zhou Xuhong, Li Baizhan. Cultivation of Top Innovative Talents in Universities in the Era of Internationalization Leading Top Innovation [J]. Higher Education in China, 2018, 01, 18. 